\title{
Composição físico-química e valores energéticos dos resíduos de goiaba e tomate para frangos de corte de crescimento lento ${ }^{1}$
}

\author{
Edney Pereira da Silva ${ }^{2}$, Demósthenes Arabutan Travassos da Silva ${ }^{2}$, Carlos Bôa-Viagem \\ Rabello ${ }^{3}$, Rodrigo Barbosa Lima ${ }^{2}$, Michele Bernardino Lima ${ }^{4}$, Jorge Vitor Ludke ${ }^{5}$
}

\author{
1 Projeto financiado pela Fundação de Amparo à Ciência e Tecnologia do Estado de Pernambuco (FACEPE). \\ 2 Programa de Pós-Graduação em Zootecnia pela Universidade Federal Rural de Pernambuco - UFRPE. Av. Dom Manoel de Medeiros, s/n, \\ CEP: 5217-900, Recife, PE. \\ ${ }^{3}$ DZ/UFRPE - Bolsista do CNPq. \\ ${ }^{4}$ Bolsista do PIBIC/CNPq, DZ/UFRPE. \\ ${ }^{5}$ EMBRAPA - Suínos e Aves.
}

RESUMO - Objetivou-se determinar a composição físico-química e o valor energético dos farelos de goiaba e de tomate para frangos de corte de crescimento lento. Analisou-se a composição químico-fisica e, em seguida, realizou-se ensaio de metabolismo utilizando-se 60 frangos da linhagem Caipirão, com 65 dias de idade, distribuídos ao acaso em três tratamentos e cinco repetições de quatro aves por unidade experimental. Os tratamentos consistiram de uma ração-referência e duas rações-teste, formuladas com $70 \%$ da ração-referência e 30\% de farelo de goiaba ou tomate. O experimento teve duração de dez dias, cinco para adaptação das aves às rações e cinco para coleta total das excretas. A composição químico-física dos farelos de tomate e de goiaba (na matéria natural) foi: 90,81 e 91,96\% de matéria seca (MS); 10,09 e 21,74\% de proteína bruta (PB); 11,71 e 12,01\% de extrato etéreo (EE); 1,25 e 4,76\% de matéria mineral (MM); 55,62 e 43,66\% de fibra bruta (FB); 64,06 e 51,53\% de fibra em detergente neutro (FDN); 57,38 e 42,22\% de fibra em detergente ácido (FDA); 6,67 e 9,32\% de hemicelulose; 4.290 e $4.368 \mathrm{kcal} / \mathrm{kg}$ de energia bruta (EB), 576,32 e 201,90 g/L de densidade; e 1.271,56 e 1.092,66 $\mu \mathrm{m}$ de diâmetro geométrico médio, respectivamente. Para os aminoácidos, os valores encontrados foram: 0,17 e 0,33\% de metionina; 0,32 e $0,30 \%$ de cistina; 0,16 e 1,12\% de lisina; 0,23 e $0,75 \%$ de treonina; 1,47 e $1,57 \%$ de arginina; 0,32 e $0,78 \%$ de isoleucina; 0,71 e $1,27 \%$ de leucina; 0,39 e $0,90 \%$ de valina; 0,25 e $0,43 \%$ de histidina; 0,44 e $0,93 \%$ de fenilalanina; 0,85 e $1,08 \%$ de glicina; 0,42 e $0,99 \%$ de serina; 0,30 e 1,05\% de prolina; 0,35 e 0,945 de alanina; 0,97 e 2,19\% de ácido aspartico; 1,91 e 3,105 de ácido glutâmico, respectivamente. Os valores de energia metabolizável aparente corrigida, com base na matéria natural, foram 1.436 e $1.969 \mathrm{kcal} / \mathrm{kg}$, respectivamente.

Palavras-chave: aminoácidos, energia metabolizável, frango de corte, subprodutos agroindustriais

\section{Physicochemical composition and energy and nutritional characteristics of guava and tomato residues for free range broilers}

\begin{abstract}
The objective of this work was to determine the physicochemical composition and metabolizable energy values of guava and tomato meal for free range broilers. The physicochemical composition was analyzed and later the metabolism assay was performed with sixty Caipirão lineage 65-day-old free range broilers distributed in a completely randomized design with three treatments and five replicates of four birds each. The treatments were: reference diet and two test diets, one with $70 \%$ of reference diet and $30 \%$ of guava residue meal and another with $30 \%$ of tomato residue meal. The experiment lasted ten days, five for adaptations and five for the total excreta collection. The physicochemical composition of the guava and tomato residue was: 90.81 and $91.96 \%$ of DM; 10.09 and $21.74 \%$ of CP; 11.71 and $12.01 \%$ of EE; 1.25 and $4.76 \%$ of ASH, 55.62 and $43.66 \%$ of CF; 64.06 and $51.53 \%$ of NFD; 57.38 and $42.22 \%$ of AFD; 6.67 and $9.32 \%$ of hemicellulose; 4,724 and 4,750 kcal/kg GE, 576.32 and $201.90 \mathrm{~g} / \mathrm{L}$ densities and geometric diameter of the particles $1,271.56$ and $1,092.66 \mu \mathrm{m}$. The amino acids profile was: 0.17 and $0.33 \%$ of methionine; 0.32 and $0.30 \%$ of cystine; 0.16 and $1.12 \%$ of lysine; 0.23 and $0.75 \%$ of threonine; 1.47 and $1.57 \%$ of arginine; 0.32 and $0.78 \%$ of isoleucine; 0.71 and $1.27 \%$ of leucine; 0.39 and $0.90 \%$ of valine; 0.25 and $0.43 \%$ of histidine; 0.44 and $0.93 \%$ of phenylalanine; 0.85 and $1.08 \%$ of glycine; 0.42 and $0.99 \%$ of serine; 0.30 and $1.05 \%$ of proline; 0.35 and 0.945 of alanine; 0.97 and $2.19 \%$ of aspartic acid; 1.91 and 3.105 of glutamic acid, respectively. The apparent metabolizable energy values were: 1.436 and $1.969 \mathrm{kcal} / \mathrm{kg}$, respectively, for guava and tomato residues.
\end{abstract}

Key Words: amino acid, free range broilers, metabolizable energy, residue by-products 


\section{Introdução}

A avaliação constante da composição físico-química e energética de alimentos para aves é extremamente importante, principalmente de ingredientes alternativos, como os resíduos da agroindústria, que normalmente não são utilizados de forma racional na alimentação de animais ou são descartados.

No Brasil estima-se taxa anual de processamento de 1,28 milhões de toneladas de tomate pela indústria (Silva et al., 2003), gerando 256 mil toneladas de resíduos. Dessas perdas, 20\% ocorrem durante o processamento, segundo as indústrias de processamento de tomate. No caso do resíduo da goiaba, a GOIABRAS (2003) estima que cerca de 202 mil toneladas de goiaba foram processadas pela indústria e que $6 \%$ é semente, o que corresponde a aproximadamente 12 mil toneladas de resíduos por ano.

Esses resíduos, ao saírem da indústria, apresentam alto teor de umidade, que, no resíduo de goiaba, pode chegar a 53\% (Silva et al., 2006) e, no resíduo de tomate, pode ultrapassar 85\% (Silva et al., 2006a). Essa característica tem limitado o uso desses resíduos in natura. O resíduo de tomate é um subproduto da agroindústria e resulta da moagem de sementes, cascas e aparas fibrosas dos pedúnculos de tomate. É caracterizado pelo seu perfil em aminoácidos (Cantarelli et al., 1989) e lipídeos (Cantarelli et al., 1993) e por seu conteúdo fibroso (Squires et al., 1992). O resíduo de goiaba é composto de polpa e principalmente sementes, que também possuem quantidades significativas de ácido graxo insaturado e matéria fibrosa (Prasad \& Azeemoddin, 1994). Entretanto, de acordo com Fontanari (2006), não há dados na literatura sobre as características da fração protéica da semente de goiaba.

Poucos estudos foram realizados com esses ingredientes e, no resíduo de tomate, especificamente, os valores de energia metabolizável descritos na literatura são: $1.760 \mathrm{kcal} / \mathrm{kg}$ (NRC, 1971, citado por Jafari et al., 2006), $2.950 \mathrm{kcal} / \mathrm{kg}$ e $3.240 \mathrm{kcal} / \mathrm{kg}$ de energia metabolizável verdadeira (EMVn) para galos cecectomizados e galos normais, respectivamente (Persia et al., 2003), $1.956 \mathrm{kcal} / \mathrm{kg}$ de de energia metabolizável aparente (EMAn) para frangos de corte (Silva et al., 2006b) e $2.806 \mathrm{kcal} / \mathrm{kg}$ de EMAn para poedeiras (Loureiro et al., 2006). O valor de EMAn do resíduo de goiaba, determinado com galinhas de postura, foi de $1.900 \mathrm{kcal} / \mathrm{kg}$ (Guimarães et al., 2006).

Em frangos caipiras, a avaliação nutricional de ingredientes alternativos torna-se ainda mais importante, pois aves dessa categoria apresentam menor exigência em comparação a frangos de corte de linhagem comercial, o que possibilita a formulação de rações com menores densidades nutricionais e permite maior inclusão desses ingredientes (Lima, 2007).

Assim, objetivou-se com este trabalho determinar a composição físico-química e os valores energéticos dos farelo de goiaba e de tomate para frangos corte de crescimento lento.

\section{Material e Métodos}

O experimento foi desenvolvido no galpão experimental do Setor de Avicultura do Departamento de Zootecnia da Universidade Federal Rural do Pernambuco, DZ-UFRPE. Inicialmente os resíduos de goiaba e de tomate foram secos em galpão com orientação leste-oeste, recebendo ventilação, onde foram revolvidos no início de cada dia, durante os 15 dias de pré-secagem. Ao final da pré-secagem, os materiais foram moídos em peneiras de $6 \mathrm{~mm}$ para obtenção dos farelos de goiaba e de tomate, que, posteriormente, foram armazenados em sacos com capacidade para $25 \mathrm{~kg}$.

Uma amostra foi enviada para o o Laboratório de Nutrição Animal do Departamento de Zootecnia da Universidade Federal Rural de Pernambuco (LNA/DZ/UFRPE) para determinação da composição em matéria seca (MS), proteína bruta (PB), extrato etéreo (EE), fibra bruta (FB), fibra em detergente neutro (FDN), fibra em detergente ácido (FDA), matéria mineral (MM) e energia bruta (EB), da densidade do alimento (Densd) e da análise da granulometria, por meio do diâmetro geométrico médio (DGM) das partículas do resíduo. Outra amostra foi enviada ao Laboratório da Empresa Degussa para determinação da composição em aminoácidos: metionina, cistina, metionina+cistina, lisina, treonina, arginina, isoleucina, leucina, valina, histidina, fenilalanina, glicina, serina, prolina, alanina, ácido aspártico e ácido glutâmico.

As análises químicas foram realizadas de acordo com metodologias descritas por Silva \& Queiroz (2002). A análise de energia bruta foi feita em bomba calorimétrica na Universidade Federal do Ceará, de acordo com a metodologia reportada por Silva \& Queiroz (2002) e a de granulometria, segundo procedimento descrito por Zanotto \& Bellaver (1996), com montagem do conjunto de peneiras vibratórias, utilizando-se o equipamento Viatest 76773 Kuhardt com seis peneiras $(4 ; 2 ; 1,20 ; 0,60 ; 0,30 ; 0,15 \mathrm{~mm})$ mais o fundo, sobrepostas em ordem crescente de abertura das malhas. O diâmetro geométrico médio (DGM) foi estimado por meio das fórmulas de Handerson \& Perry (1955), em que DGM $(\mathrm{mm})=104,14 \times 2^{\mathrm{MF}}$.

Os coeficientes de metabolização da matéria seca e da energia bruta e os valores de energia metabolizável aparente (EMA) e energia metabolizável aparente corrigida para 
balanço de nitrogênio (EMAn) dos farelos de goiaba e tomate para frangos de corte de crescimento lento foram obtidos em ensaio de metabolismo, pelo método de coleta total de excretas. Para isso, foram alojadas 60 aves da linhagem comercial Caipirão de crescimento lento, com média de 65 dias de idade, em galpão coberto com telhas de fibrocimento, dotado de gaiolas metálicas de dimensões $50 \times 40 \times 45 \mathrm{~cm}$.

As aves foram pesadas individualmente no início do experimento para ajuste da distribuição por peso, de modo a obter peso uniforme entre os tratamentos $(1.395,35 \pm$ 69,75 g) e distribuídas em três tratamentos com cinco repetições, em delineamento inteiramente casualizado com quatro aves por unidade experimental. Os tratamentos consistiram de uma ração-referência à base de milho e soja, e duas rações-teste, compostas de $70 \%$ da ração-referência e 30\% de resíduo de tomate ou de goiaba (Tabela 1). A ração-referência foi formulada com base nas tabelas de composição de alimentos de Rostagno et al. (2005).

Água e as rações fareladas foram oferecidas diariamente à vontade. Adotou-se um programa de luz natural, com 12 horas luz/dia. Quando as aves completaram 60 dias, iniciou-se o período de adaptação às dietas (cinco dias),

Tabela 1 - Composição das rações experimentais

\begin{tabular}{lc}
\hline Ingrediente & \% da matéria natural \\
\hline Milho grão & 67,143 \\
Farelo de soja 45\% & 26,360 \\
Farelo de trigo & 2,744 \\
Fosfato bicálcico & 1,762 \\
Calcário calcítico & 1,254 \\
Sal comum & 0,457 \\
DL-metionina 99\% & 0,092 \\
Suplemento vitamínico ${ }^{1}$ & 0,100 \\
Suplemento mineral ${ }^{2}$ & 0,050 \\
Cloreto de colina 60\% & 0,040 \\
Total & 100,00 \\
\hline Composição calculada & \\
\hline EMAn, kcal/kg $/$ \% & 2.900 \\
Proteína bruta, \% & 18,00 \\
Cálcio, \% & 1,000 \\
Fósforo disponível, \% & 0,435 \\
Metionina+cistina total \% & 0,682 \\
Lisina total, \% \% & 0,909 \\
Treonina total, \% & 0,698 \\
Triptofano total, \% & 0,216 \\
Colina adicionada, \% & 0,240 \\
Ácido linoléico, \% & 1,405 \\
Sódio, \% & 0,201 \\
\hline Suplo &
\end{tabular}

1 Suplemento vitamínico (composição por kilograma do produto): vit. A $9.000 .000 \mathrm{UI}$; vit. $\mathrm{D}_{3}-2.500 .000 \mathrm{UI}$; vit. E - $20.000 \mathrm{UI}$; vit. $\mathrm{K}_{3}-2.500 \mathrm{mg}$; vit. $\mathrm{B}_{1}-1.500 \mathrm{mg}$; vit. $\mathrm{B}_{2}-6.000 \mathrm{mg}$; vit. $\mathrm{B}_{6}-3.000 \mathrm{mg}$; vit. $\mathrm{B}_{12,}, 12.000 \mathrm{mg}$; ácido nicotínico - $24.000 \mathrm{mg}$; ácido pantotênico - $12.000 \mathrm{mg}$; ácido fólico - $800 \mathrm{mg}$.

2 Suplemento mineral (composição por kilograma do produto): Se - $250 \mathrm{mg}$; $\mathrm{Cu}$ 18.000 mg; Zn - 120.000 mg; I - 2.000 mg; Fe - 60.000 mg; Mn - 120.000 mg. seguido do período de coleta das excretas (cinco dias). O óxido férrico em pó foi acrescido às rações experimentais na proporção de $1,0 \%$ como marcador fecal no início e final da coleta de excretas das aves. As excretas eram colhidas duas vezes ao dia em dois horários, às 8 h e às 16 h, em bandejas cobertas com plásticos sob cada gaiola.

As excretas colhidas foram acondicionadas em sacos plásticos devidamente identificados e armazenadas em freezer a $-20^{\circ} \mathrm{C}$ até o final do experimento, quando foram homogeneizadas por unidade experimental. Os coeficientes de digestibilidade aparente da matéria seca e os valores de EMA e EMAn dos ingredientes foram calculados utilizando-se fórmulas propostas por Matterson et al. (1965).

Considerando os valores de energia bruta (EB) e a EMAn dos ingredientes, foram calculados os coeficientes de metabolização, segundo equação preconizada pelo ARC (1980), em que CMEB = $($ EMAn/EB $) \times 100$. Os resultados foram submetidos à análise estatística pelo programa computacional SISVAR ${ }^{\circledR}$ (Ferreira, 2003) e as médias, comparadas pelo teste t a $5 \%$ de probabilidade.

\section{Resultados e Discussão}

Os valores de proteína bruta e extrato etéreo no farelo de goiaba analisado foram superiores aos verificados por Silva (1999), enquanto os valores da fração fibrosa foram inferiores (Tabela 2). Esses autores analisaram o resíduo de goiaba proveniente de duas indústrias processadoras e obtiveram a seguinte variação na composição química: 91,9 a 93\% de matéria seca; 8,6 a 9,4\% de proteína bruta; 9,8 a 11,3\% de extrato etéreo; 77,1 a 74,2\% de FDN; e 58,7 a 56,9\% para a FDA.

Prasad \& Azeemoddin (1994) encontraram 4,1\% de umidade, 7,6\% de proteína bruta, 16,0\% de gordura bruta,

Tabela 2 - Composição dos farelos de goiaba e tomate ${ }^{1}$

\begin{tabular}{lcc}
\hline Item & Farelo de goiaba & Farelo de tomate \\
\hline Matéria seca, \% & 90,81 & 91,96 \\
Proteína bruta, \% & 10,09 & 21,74 \\
Extrato etéreo, \% & 11,71 & 12,01 \\
Matéria mineral, \% & 1,25 & 4,76 \\
Fibra bruta, \% & 55,62 & 43,66 \\
Fibra em detergente neutro, \% & 64,06 & 51,53 \\
Fibra em detergente ácido, \% & 57,38 & 42,22 \\
Hemicelulose, \% & 6,67 & 9,32 \\
Extrativo não nitrogenado, \% & 12,74 & 9,19 \\
Carboidrato não estrutural, \% & 4,30 & 1,32 \\
Energia bruta, kcal/kg & 4290 & 4368 \\
Densidade, g/L & 576,32 & 201,90 \\
Diâmetro geométrico & $1.271,56$ & $1.092,66$ \\
médio, $\mu$ m & & \\
\hline
\end{tabular}

${ }^{1}$ Valores expressos com base na matéria natural. 
61,4\% de fibra bruta e 0,93\% de matéria mineral. Na literatura, são descritos valores bem distintos para os principais nutrientes do farelo de tomate. O percentual de proteína bruta encontrado localizou-se entre os valores apresentados por Silva et al. (2005) e Cantarelli et al. (1989): 18,86\% (utilizando fator de 6,25) e 33,71\% (utilizando fator de $5,85)$, respectivamente. Para o extrato etéreo, o valor de $11,65 \%$ é menor que 8,45 e maior que $20,1 \%$, obtidos por Silva et al. (2005) e Persia et al. (2003), respectivamente. O conteúdo de fibra bruta encontrado neste trabalho foi próximo aos valores registrados na literatura, de 38,25 a 41,78\%, conforme descrito por Silva et al. (2005) e Cantarelli et al. (1993), respectivamente.

Os valores nutricionais dos ingredientes foram satisfatórios para utilização em dietas para aves de crescimento lento, especialmente os de extrato etéreo e proteína bruta, no entanto, esse ingredientes possuem alto percentual de fibra bruta, o que possivelmente refletiu no conteúdo energético dos farelos, provocando diluição na energia metabolizável, uma vez que, no trato digestório desses animais, não há secreção endógena de enzimas que atuam sobre as ligações $\beta$ presentes nos polissacarídeos contidos na fração fibrosa da matéria seca, além de baixa atividade cecal.

Essas variações na composição química são condicionadas por diversos fatores como: variedade do fruto, incluindo a proporção de sementes e cascas; estado de maturação dos frutos, pois, em estágio avançado de maturação, possuem maior percentual de umidade; manejo e tratos culturais, como reposição mineral no solo exigido pela cultura e nível tecnológico das unidades beneficiadoras na separação das sementes das cascas e outros, que se correlacionam ao conteúdo protéico; quantidade de água utilizada durante o processamento, percebida no rendimento de matéria seca para obtenção do farelo (Silva et al., 2005).

O valor encontrado para densidade do farelo de tomate foi inferior ao do milho e do farelo de soja, convencionalmente utilizados em dietas para aves. O milho, segundo Rodrigues et al. (2001), apresenta densidade que varia de 724,5 a 757,7 g/L, enquanto o farelo de soja tem densidade de 639,3 a 675,2 g/L (Rodrigues et al., 2002). A densidade do farelo de goiaba determinada neste trabalho foi próxima às densidades do milho e do farelo de soja.

Essa diferença de densidade entre os ingredientes está relacionada à composição química da parede celular, principalmente à proporção de pectinas, celulose-hemicelulose e proteínas, uma vez que o grau de porosidade depende do domínio pectínico (Ezequiel, 2004), presente em 7\% da matéria seca do fruto (Silva et al., 2003). A presença desse domínio se reflete no arranjo estrutural da fração fibrosa da parede celular e influencia a densidade mais expressivamente que o quantitativo fibroso no material, visto que o farelo de tomate possui aproximadamente $51 \%$ de fibra em detergente neutro, ao passo que esta fração corresponde a $64 \%$ da matéria seca do farelo de goiaba.

Entre os fatores reguladores de consumo descritos por Gonzales et al. (2002), os gastrintestinais estão relacionados ao limite físico, ou seja, ao enchimento do papo e da moela, que, em curto prazo, se repercute na capacidade física de ingestão de alimentos, pois atinge o máximo de distensão da musculatura do trato gastrintestinal, sobretudo quando utilizados alimentos de menor densidade. Desta forma, a densidade do alimento consiste em informação importante e deve ser considerada na elaboração de estratégias alimentares, sobretudo quando se pretende formular ração de custo mínimo.

O diâmetro geométrico médio verificado para os farelos de goiaba $(1.271,56 \mu \mathrm{m})$ e tomate $(1.092,66 \mu \mathrm{m})$ neste trabalho situou-se acima do desejável, conforme Zanotto et al. (1996). Esses autores concluíram que valores próximos a $1.000 \mu \mathrm{m}$ possibilitam conciliar economia de energia elétrica (por melhorar o rendimento da moagem) sem alterar o valor energético do alimento.

As quantidades de aminoácido contidas no farelo de tomate foram superiores às encontradas no milho e farelo de trigo por Albino et al. (1992), especialmente os aminoácidos sulfurosos (Tabela 3). A maior parte dos aminoácidos ingeridos pelas aves está na forma de proteína que, ao serem digeridas, liberam os aminoácidos para absorção. No entanto, a concentração de aminoácido varia amplamente

Tabela 3 - Composição aminoacídica dos farelos de goiaba e tomate

\begin{tabular}{|c|c|c|c|c|}
\hline \multirow[t]{2}{*}{ Aminoácido } & \multicolumn{2}{|c|}{ Farelo de goiaba } & \multicolumn{2}{|c|}{ Farelo de tomate } \\
\hline & $\mathrm{MN}, \%^{1}$ & $\mathrm{~PB}, \%^{2}$ & $\mathrm{MN}, \%^{1}$ & $\mathrm{~PB}, \%^{2}$ \\
\hline Metionina & 0,17 & 1,60 & 0,33 & 1,52 \\
\hline Cistina & 0,32 & 2,98 & 0,30 & 1,37 \\
\hline Metionina+Cistina & 0,49 & 4,58 & 0,63 & 2,89 \\
\hline Lisina & 0,16 & 1,52 & 1,12 & 5,12 \\
\hline Treonina & 0,23 & 2,13 & 0,75 & 3,42 \\
\hline Arginina & 1,47 & 13,70 & 1,57 & 7,19 \\
\hline Isoleucina & 0,32 & 2,97 & 0,78 & 3,58 \\
\hline Leucina & 0,71 & 6,60 & 1,27 & 5,83 \\
\hline Valina & 0,39 & 3,62 & 0,90 & 4,12 \\
\hline Histidina & 0,25 & 2,30 & 0,43 & 1,95 \\
\hline Fenilalanina & 0,44 & 4,10 & 0,93 & 4,24 \\
\hline Glicina & 0,85 & 7,95 & 1,08 & 4,93 \\
\hline Serina & 0,42 & 3,88 & 0,99 & 4,54 \\
\hline Prolina & 0,30 & 2,80 & 1,05 & 4,78 \\
\hline Alanina & 0,35 & 3,24 & 0,94 & 4,29 \\
\hline Ácido aspártico & 0,97 & 9,04 & 2,19 & 10,00 \\
\hline Acido glutâmico & 1,91 & 17,80 & 3,10 & 14,20 \\
\hline
\end{tabular}

${ }^{1}$ Valores expressos com base na matéria natural do farelo.

${ }^{2}$ Valores expressos com base na proteína bruta do farelo. 
entre os alimentos e pode ser influenciada por diversos fatores, entre eles, a fertilidade do solo, a estação do ano e o processamento adotado (Albino et al., 1992). Desta forma, Cantarelli et al. (1989) verificaram que o aumento da temperatura no processamento diminui a concentração de aminoácido nas sementes de tomate, exceto para metionina e cistina, que aumentaram 10,73 e 11,57\%, respectivamente.

O perfil de aminoácido do farelo de tomate determinado neste trabalho situou-se próximo ao revelado por Persia et al. (2003), que obtiveram as seguintes variações nos conteúdos de aminoácidos essenciais: arginina, 1,84 a 2,43\%; fenilalanina, 1,04 a 1,25\%; histidina, 0,49 a 0,61\%; isoleucina, 0,89 a 1,04\%; leucina, 1,41 a 1,66\%; lisina, 1,19 a 1,48\%; metionina, 0,34 a 0,44\%; treonina, 0,73 a $0,90 \%$; e valina, 1,01 a 1,16\%. Para os conteúdos de aminoácidos não-essenciais, as variações foram: alanina, 1,11 a 1,12\%; ácido aspártico, 2,40 a 2,79\%; ácido glutâmico, 4,29 a 5,01\%; cistina, 0,37 a $0,43 \%$; prolina, 1,29 a 1,44\%; e serina, 1,16 a 1,28\%. Além desses aminoácidos, os autores citaram ainda a concentração de triptofano, de 0,82 a 0,98\%.

A proporção de aminoácidos na proteína do farelo de tomate diferiu daquela descrita por Cantarelli et al. (1989), de $9,71 \%$ de arginina; 5,26\% de fenilalanina; $3,83 \%$ de histidina; 4,18\% de isoleucina; 5,84\% de leucina; 8,30\% de lisina; 2,46\% de metionina; 3,62\% de treonina; 4,06\% de valina; 3,57\% de alanina; $11,17 \%$ de ácido aspártico; 13,45\% de ácido glutâmico; $2,56 \%$ de cistina; 5,32\% de glicina; $6,08 \%$ de prolina; $4,46 \%$ de serina; e $5,02 \%$ de tirosina, sobretudo para os aminoácidos essenciais arginina, lisina, fenilalanina, isoleucina, histidina, metionina e os não-essenciais prolina, glicina e cistina.

Os aminoácidos essenciais, como a arginina, fenilalanina, isoleucina e valina, bem como os não-essenciais ácido aspártico, ácido glutâmico, cistina e glicina, do farelo de goiaba foram encontrados em quantidades superiores à do milho avaliado por Albino et al. (1992). Os teores de histidina, metionina e serina no farelo de goiaba foram semelhantes aos do milho e diferiram dos demais aminoácidos (leucina, lisina, treonina, alanina, e prolina), situando-se abaixo dos valores apresentados para o milho.

Os dez principais aminoácidos que compõem a proteína bruta das sementes do farelo de goiaba, em ordem decrescente, são: ácido glutâmico, arginina, ácido aspártico, glicina, leucina, aminoácidos sulfurosos (metionina+cistina), fenilalanina, serina, valina e alanina. Contudo, não foram encontradas até o momento na literatura informações sobre o perfil de aminoácido do farelo de goiaba.

Os desvios em torno das médias e os coeficientes de variação indicaram baixos valores de consumo de matéria seca (CMS), coeficiente de metabolizabilidade da matéria seca (CMMS), energia metabolizável aparente (EMA), energia metabolizável aparente corrigida (EMAn) e balanço de nitrogênio (BN) das dietas experimentais, fato esperado em ensaios de metabolismo (Tabela 4).

Os resultados das análises das variâncias indicaram efeito da inclusão dos farelos sobre a ingestão de ração, comprovando maior consumo das rações-teste, ou seja, daquelas que continham os resíduos de goiaba e tomate. Em ensaios de metabolismo, a variação no consumo se reflete nos resultados e pode ocorrer subestimação dos valores energéticos, conforme relatos de Penz Jr. et al. (1999), sobretudo quando se utilizam alimentos que promovem redução no consumo.

Os resultados comprovaram que as aves aumentaram gradativamente o consumo de matéria seca com a diluição na oferta de energia e especialmente de aminoácido, uma vez que o balanço de nitrogênio não foi afetado. Essa

Tabela 4 - Consumo de matéria seca, coeficiente de metabolizabilidade da matéria seca, valores de energia metabolizável, balanço de nitrogênio e coeficiente de metabolização da energia bruta das rações experimentais

\begin{tabular}{|c|c|c|c|c|c|}
\hline Componente & Ração-referência & $\begin{array}{l}\text { Ração com } \\
\text { resíduo de goiaba }\end{array}$ & $\begin{array}{l}\text { Ração com } \\
\text { resíduo de tomate }\end{array}$ & $\mathrm{F}^{1}$ & $\mathrm{CV}, \%^{2}$ \\
\hline Consumo de matéria seca, g/parcela & $1.212 \pm 35 b$ & $1.509 \pm 87 \mathrm{a}$ & $1.422 \pm 98 \mathrm{a}$ & $18,993 * *$ & 5,68 \\
\hline $\begin{array}{l}\text { Coeficiente de metabolizabilidade } \\
\text { da matéria seca, \% }\end{array}$ & $82,03 \pm 1,37 a$ & $68,89 \pm 1,20 b$ & $69,66 \pm 1,92 b$ & $116,184^{* *}$ & 2,08 \\
\hline Energia metabolizável aparente, kcal/kg & $3.597 \pm 64,9 a$ & $2965 \pm 65,4 c$ & $3.166 \pm 74,1 b$ & $112,318 * *$ & 2,10 \\
\hline Balanço de nitrogênio, g & $27,34 \pm 1,93$ & $28,05 \pm 2,28$ & $28,18 \pm 1,89$ & $0,094 \mathrm{NS}$ & 7,32 \\
\hline $\begin{array}{l}\text { Energia metabolizável aparente corrigida } \\
\text { para o balanço de nitrogênio, } \mathrm{kcal} / \mathrm{kg}\end{array}$ & $3.410 \pm 58,0 a$ & $2812 \pm 60,4 c$ & $3.003 \pm 67,7 b$ & $120,346 * *$ & 2,02 \\
\hline $\begin{array}{l}\text { Coeficiente de metabolização da } \\
\text { energia bruta, \% }\end{array}$ & $80,30 \pm 1,37 a$ & $66,51 \pm 1,43 b$ & $68,07 \pm 1,53 b$ & $136,788 * *$ & 2,02 \\
\hline
\end{tabular}

\footnotetext{
a,b Média seguidas de letras diferentes na coluna diferem estatisticamente pelo teste t.

Ns Não-significativo $(\mathrm{P}>0,05)$.

** $(\mathrm{P}<0,01)$

1 Valor de $\mathrm{F}$.

2 Coeficiente de variação.
} 
diluição pode ser atribuída ao desbalanceamento da dieta e à quantidade de fibra nos ingredientes.

A determinação do coeficiente de metabolizabilidade da matéria seca é importante, pois auxilia na compreensão da fração digerível, assimilável e metabolizável do alimento, uma vez que é na matéria seca que os nutrientes estão contidos. Esses nutrientes são oxidados pelo metabolismo celular, quantificado pelo coeficiente de metabolizabilidade da energia bruta, que, em frangos de corte de crescimento lento, é baixo (Tabela 5). No entanto, neste estudo o coeficiente de metabolizabilidade da matéria seca foi semelhante ao descrito por Lima (2007) para outros ingredientes, recentemente estudados em aves de crescimento lento.

Atualmente, a literatura é pobre em informações sobre o aproveitamento dos nutrientes de alimentos como os resíduos de goiaba e de tomate. Contudo, informações sobre a digestibilidade dos nutrientes e da energia determinados com tilápia são disponibilizadas por Sales et al. (2004), que obtiveram para os farelos de goiaba e de tomate coeficiente de digestibilidade da matéria seca de 58,07 e $60,27 \%$, respectivamente, e para a energia coeficientes de 27,18 e $40,59 \%$, respectivamente.

Lima (2007), trabalhando com aves de crescimento lento, observou que a capacidade de metabolização da energia do gérmen integral de milho e do farelo de glúten 21 aumentou com o avanço da idade e apresentou valor máximo aos 75 dias de idade.

Apesar do aumento na metabolizabilidade proporcionado pela idade, os coeficientes de metabolizabilidade da matéria seca e da energia bruta registrados neste trabalho foram inferiores aos determinados em poedeiras comerciais por Loureiro et al. (2006), que verificaram para o farelo de tomate superioridade de $18 \%$ para os coeficientes de metabolizabilidade da matéria seca e $36 \%$ para o coeficiente de metabolizabilidade da energia bruta.

O coeficiente de metabolizabilidade da matéria seca do farelo de goiaba determinado com frangos de corte caipira foi 9\% superior ao obtido por Guimarães et al. (2006), no entanto, as aves de crescimento lento metabolizaram menos a energia, com diferença de $22 \%$.

Os resultados observados neste estudo sugerem que as aves de crescimento lento foram menos eficiente no aproveitamento da energia em comparação a poedeiras comerciais. Desta forma, os dados obtidos corroboram a hipótese de que a variação genética afeta a capacidade de digerir e absorver os nutrientes, assim como em alguns trabalhos clássicos (Sibbald \& Slinger, 1963; Sibbald, 1976) e recentes (Lima, 2007).

Os valores de energia metabolizável determinados com frangos de corte de crescimento lento (Tabela 5) foram semelhantes aos obtidos com frangos de corte de linhagem industrial por Silva et al. (2006b), que verificaram valores de $2.045 \pm 0,304$ e $1.956 \pm 0,296 \mathrm{kcal} / \mathrm{kg}$ para EMA e EMAn, respectivamente. Apesar de semelhantes, os valores determinados com frangos de crescimento lento foram mais estáveis e variaram menos em torno da média. Isso indica que essas aves podem ser mais tolerantes a altos níveis de fibra na dieta e podem suportar maiores níveis de fibra na ração.

Em poedeiras comerciais, verifica-se diferença de $1.320 \mathrm{kcal} / \mathrm{kg}$ para EMA e $837 \mathrm{kcal} / \mathrm{kg}$ para EMAn, conforme achados de Loureiro et al. (2006) em relação ao farelo de tomate. Sibbald et al. (1960) destacaram a idade entre os fatores que afetam a digestibilidade dos nutrientes dos alimentos, por conferir maior capacidade digestiva, especialmente para os alimentos fibrosos.

Persia et al. (2003) separaram as sementes das cascas, películas e aparas, ou seja, concentraram a fração protéica e lipídica do material e encontraram valores de energia metabolizável verdadeira corrigida para o balanço de nitrogênio em galos cecectomizados e inteiros, respectivamente, de 2.954 e $3.204 \mathrm{kcal} / \mathrm{kg}$.

As aves utilizadas neste trabalho demonstraram menor aproveitamento do farelo de goiaba (-611 e -388 kcal/kg de EMA e EMAn, respectivamente) em comparação a poedeiras comerciais observadas por Guimarães et al. (2006).

Tabela 5 - Consumo de matéria seca, coeficiente de metabolizabilidade da matéria seca, valores de energia metabolizável e coeficiente de metabolização da energia bruta dos resíduos de goiaba e tomate

\begin{tabular}{|c|c|c|c|c|}
\hline & \multicolumn{2}{|c|}{ Resíduo de goiaba } & \multicolumn{2}{|c|}{ Resíduo de tomate } \\
\hline & \% matéria natural & $\%$ matéria seca & \% matéria natural & $\%$ matéria seca \\
\hline Consumo de matéria seca, g/parcela & $466 \pm 27,0$ & $431 \pm 25,0$ & $434 \pm 29,8$ & $398 \pm 27,4$ \\
\hline $\begin{array}{l}\text { Coeficiente de metabolizabilidade da } \\
\text { matéria seca, \% }\end{array}$ & $39,53 \pm 3,87$ & $36,58 \pm 3,58$ & $41,48 \pm 6,30$ & $38,11 \pm 5,79$ \\
\hline Energia metabolizável aparente, kcal/kg & $1.633 \pm 115$ & $1.512 \pm 106$ & $2.256 \pm 212$ & $2.073 \pm 195$ \\
\hline $\begin{array}{l}\text { Energia metabolizável aparente corrigida } \\
\text { pelo balanço de nitrogênio, } \mathrm{kcal} / \mathrm{kg}\end{array}$ & $1.552 \pm 106$ & $1.436 \pm 98$ & $2.143 \pm 192$ & $1.969 \pm 176$ \\
\hline $\begin{array}{l}\text { Coeficiente de metabolizabilidade da } \\
\text { energia bruta, } \%\end{array}$ & $30,23 \pm 2,06$ & $27,98 \pm 1,91$ & $41,68 \pm 3,73$ & $38,29 \pm 3,43$ \\
\hline
\end{tabular}




\section{Conclusões}

Os farelos de tomate e goiaba têm composição físicoquímica favorável à utilização em dietas para aves de crescimento lento. Os valores de energia metabolizável aparente corrigida para o balanço de nitrogênio desses alimentos, com base na matéria natural, foram 1.436 e 1.969 kcal $/ \mathrm{kg}$, respectivamente.

\section{Agradecimentos}

À Fundação de Amparo a Ciência e Tecnologia do estado de Pernambuco (FACEPE), à empresa Degussa, pelas análises de aminoácidos, à empresa Palmeiron Ltda, pela doação dos resíduos de goiaba e tomate, ao Sítio Boa Vista, pelo empréstimo das aves e à MCASSAB, pela doação dos suplementos vitamínico e mineral.

\section{Literatura Citada}

AGRICULTURAL RESEARCH COUNCIL - ARC. The nutritional requirement of ruminant livestock. London: $C A B$ International, 1980. 351p.

ALBINO, L.F.T.; ROSTAGNO, H.S.; FONSECA, J.B. et al. Determinação dos valores de aminoácidos metabolizáveis e proteína digestível de alimentos para aves. Revista da Sociedade Brasileira de Zootecnia, v.21, n.6, p.1059-1068, 1992.

CANTARELLI, P.R.; PALMA, E.R.; CARUSO, J.G.B. Composition and amino acid profiles of tomato seeds from canning wastes. Acta Alimentaria, v.18, n.1, p.13-18, 1989.

CANTARELLI, P.R.; REGITANO-D ARCE, M.A.B.; PALMA, E.R. Physicochemical characteristics and fatty acid composition of tomato seed oils from processing wastes. Scientia Agricola, v.50, n.1, p.117-120, 1993.

EZEQUIEL, J.M.B. Recentes enfoques nas avaliações da fibra e do amido In: CONGRESSO NORDESTINO DE PRODUÇÃO ANIMAL, 3., 2004, Campina Grande. Anais... Campina Grande: Sociedade Nordestina de Produção Animal/Universidade Federal da Paraíba [2004]. (CD-ROM).

FERREIRA, D.F. Sistema de análise de variância - Sisvar. Versão 4.6 (Build 6.0). Lavras: DEX/UFLA, 2003.

FONTANARI, G.G. Isolado protéico de farinha de semente de goiaba (Psidium guajava) caracterização de propriedades funcionais e térmicas. 2006. 117f. Dissertação (Mestrado em Alimentos e Nutrição) - Universidade Estadual Paulista, Faculdade de Ciências Farmacêuticas, Araraquara, 2006.

GOIABRAS. [2003]. Associação Brasileira dos Produtores de Goiaba. Disponível em: <http://www.goiabras.org.br/> Acesso em: 6/5/2007.

GONZALES, E. Ingestão de alimentos: mecanismos regulatórios: In: MACARI, M.; FURLAN, R.L.; GONZALES, E. (Eds.). Fisiologia aviaria aplicada a frangos de corte. Jaboticabal: FUNEP/UNESP, 2002. p.187-199.

GUIMARÃES, A.A.S.; RABELLO, C.B.V.; LOUREIRO, R.R.S. et al. Valores de energia metabolizável e coeficientes de metabolização aparente da matéria seca e da energia bruta do farelo de goiaba para poedeiras comerciais, In: ZOOTEC. 41., Recife. Anais... Recife: Associação Brasileira de Zootecnistas/ Adaltech, [2006]. (CD-ROM).

HANDERSON, S.M.; PERRY, R.L. Agricultural process engineering. New York: John Wiley \& Sons, 1955. 402p.
JAFARI, M.; PIRMOHAMMADI, R.; BAMPIDIS, V. et al. The use of dried tomato pulp in diets of laying hens. International Journal of Poultry Science, v.5, n.7, p.618-622, 2006.

LIMA, S.B.P. Avaliação nutricional de co-produtos o milho para frango de corte caipira. 2007. 48f. Dissertação (Mestrado em Zootecnia) - Universidade Federal Rural de Pernambuco, Recife, 2007.

LOUREIRO, R.R.S.; RABELLO, C.B.V.; DUTRA JR., W.M. et al. 2006. Valores de energia metabolizável e coeficientes de metabolização aparente da matéria seca e da energia bruta do farelo de tomate para poedeiras comerciais, In: REUNIÃO ANUAL DA SOCIEDADE BRASILEIRA DE ZOOTECNIA, 43. 2006, João Pessoa. Anais... João Pessoa: Sociedade Brasileira de Zootecnia/Convention \& Visitors Bureau [2006]. (CD-ROM).

MATTERSON, L.D.; POTTER, L.M.; STUTZ, M.W. et al. The metabolizable energy of feed ingredients for chickens. Storrs: University of Connecticut, Agricultural Experiment Station, 1965. 11p. (Research Report, 7).

PENZ JR., A.M.; KESSLER, A.M., BRUGALLI, I. Novos conceitos de energia para aves. In: SIMPÓSIO INTERNACIONAL SOBRE NUTRIÇÃO DE AVES, 1999, Campinas. Anais... Campinas: Fundação Apinco de Ciência e Tecnologia Avícolas, 1999. p.1-24

PERSIA, M.E.; PARSONS, C.M.; SCHANG, M. et al. Nutritional evaluation of dried tomato seeds. Poultry Science, v.82, n.1, p.141-146, 2003.

PRASSAD N.B.L.; AZEEMODDIN, G. Characteristics and composition of guava (Psidium guajava L.) seed and oil, Journal of the American Oil Chemists' Society, v.71, n.4, p.457-458, 1994.

RODRIGUES, P.B.; ROSTAGNO, H.S.; ALBINO, L.F.T. et al. Valores energéticos do milheto, do milho e subprodutos do milho,determinados com frangos de corte e galos adultos. Revista Brasileira de Zootecnia, v.30, n.6, p.1767-1778, 2001.

RODRIGUES, P.B.; ROSTAGNO, H.S.; ALBINO, L.F.T. et al. Valores energéticos da soja e subprodutos da soja, determinados com frangos de corte e galos adultos. Revista Brasileira de Zootecnia, v.31, n.4, p.1771-1782, 2002.

ROSTAGNO, H.S.; ALBINO, L.F.T.; DONZELE, J.L. et al. Tabelas brasileiras para aves e suínos: composição de alimentos e exigências nutricionais. Viçosa, MG: Universidade Federal de Viçosa, 2005. 186p.

SALES, P.J.P.; FURUYA, W.M.; SANTOS, V.G. et al. Valor nutritivo dos farelos do subproduto industrial do tomate ("Lycopersicum esculentum") e da goiaba ("Psidium guajava”) para a telaria do nilo ("Oreochromis niloticus") In: REUNIÃO ANUAL DA SOCIEDADE BRASILEIRA DE ZOOTECNIA, 41., 2004, Campo Grande. Anais... Campo Grande: Sociedade Brasileira de Zootecnia/ Embrapa Gado de Corte [2004] (CD-ROM).

SIBBALD, I.R. The true metabolizable energy value of several feedingstuffs measured with roosters, laying hens, turkeys and broiler hens. Poultry Science, v.55, n.2, p.1459-1463, 1976.

SIBBALD, I.R.; SLINGER, S.J. A biological assay for metabolizable energy in poultry feed ingredients together with findings which demonstrate some of the problems associated with evaluation of fats. Poultry Science, v.42, n.1, p.13-25, 1963.

SIBBALD, I.R.; SUMMERS, J.D.; SLINGER, S.J. Factors affecting the metabolizable energy content of poultry feeds. Poultry Science, v.62, n.3, p.544-556, 1960.

SILVA, D.J.; QUEIROZ, A.C. Análise de alimentos (métodos químicos e biológicos). 3.ed. Viçosa, MG: Editora UFV, 2002. 235p.

SILVA, D.A.T.; RABELLO, C.B.V.; SILVA, E.P. et al. Efeito de dois métodos de pré-secagem na composição bromatológica do resíduo do farelo de goiaba para frango de corte In: JORNADA DE ENSINO, PESQUISA E EXTENSÃO DA UFRPE CONGRESSO DE INICIAÇÃO CIENTÍFICA. 6., 2006, Recife. Anais... Recife: Universidade Federal Rural de Pernambuco [2006a]. (CD-ROM).

SILVA, E.P.; RABELLO, C.B.V.; LIRA, R.C. et al. Composição química e valores de energia metabolizável do farelo de tomate 
para frangos de corte In: REUNIÃO ANUAL DA SOCIEDADE BRASILEIRA DE ZOOTECNIA, 43., 2006, João Pessoa. Anais... João Pessoa: Sociedade Brasileira de Zootecnia/ Convention \& Visitors Bureau [2006b]. (CD-ROM).

SILVA, E.P.; RABELLO, C.B.V.; SILVA, D.A.T. et al. Composição química e rendimento do resíduo de tomate em diferentes períodos de coletas. In: JORNADA DE ENSINO, PESQUISA E EXTENSÃO DA UFRPE - CONGRESSO DE INICIAÇÃO CIENTÍFICA. 5., 2005, Recife. Anais... Recife: Universidade Federal Rural de Pernambuco [2005]. (CD-ROM).

SILVA, J.B.C.; GIORDANO, L.B.; FURUMOTO, O. et al. [2003]. Cultivo de tomate para industrialização. In: Sistema de Produção, 1., 2003, Brasília: Anais eletrônicos... Brasília: EMPRESA BRASILEIRA DE PESQUISA AGROPECUÁRIA - CENTRO NACIONAL DE PESQUISA EM HORTALIÇAS, 2003. Disponível em: <http://www.sistemasdeproducao.cnptia. embrapa.br/Fontes HTML/Tomate/TomateIndustrial/index.htm> Acesso em: 6/5/2007.
SILVA, J.D.A Composição química e digestibilidade in situ da semente de goiaba (Psidium guajava L.). 1999. 34f. Dissertação (Mestrado em Zootecnia) - Universidade Federal Rural de Pernambuco, Recife, 1999.

SQUIRES, M.W.; NABER, E.C.; TOELLE, V.D. The effects of heat, water, acid, and alkali treatment of tomato cannery wastes on growth, metabolizable energy value, and nitrogen utilization of boiler chicks. Poultry Science, v.71, n.3, p.522-529, 1992.

ZANOTTO, D.L.; BELLAVER, C. Métodos de determinação da granulometria de ingredientes para uso em rações de suínos e aves. Concórdia: Empresa Brasileira de Pesquisa Agropecuária - Centro Nacional de Pesquisa Suínos e Aves, 1996. p.1-5 (Comunicado Técnico, 215).

ZANOTTO, D.L.; GUIDONI, A.L.; ALBINO, L.F.T. et al. Efeito da granulometria de ingredientes sobre o conteúdo energético do milho para frangos corte. Concórdia: Empresa Brasileira de Pesquisa Agropecuária - Centro Nacional de Pesquisa Suínos e Aves, 1996. p.1-2 (Comunicado Técnico, 218). 